\title{
Pancoast's syndrome due to metastatic carcinoma from the stomach
}

Takahide Kodama MD, Hiroaki Satoh MD, Shinsuke Homma MD, Kiyohisa Sekizawa MD

T Kodama, H Satoh, S Homma, K Sekizawa. Pancoast's syndrome due to metastatic carcinoma of the stomach. Can Respir J 2003;10(6):330.

We describe here a case of Pancoast's syndrome due to metastatic carcinoma from the stomach. Although obtaining a tissue diagnosis is often difficult with apical lesions, transbronchial or percutaneous needle biopsy is the procedure of choice since a certain number of these cases are potentially curable.

Key Words: Gastric cancer; Metastasis; Pancoast's syndrome

\section{Un syndrome de Pancoast-Tobias causé par un carcinome métastatique de l'estomac}

Est décrit un cas de syndrome de Pancoast-Tobias causé par un carcinome métastatique de l'estomac. Bien qu'il soit souvent difficile de parvenir à un diagnostic tissulaire en cas de lésions apiques, la biopsie transbonchique ou percutanée à l'aiguille demeure l'intervention de première intention puisque certains cas ont un potentiel de guérison.
Dancoast's syndrome refers to a condition involving arm pain and Horner's syndrome that is most commonly found in patients with lung cancer of the superior sulcus invading the upper ribs or spine, lower brachial plexus and sympathetic chain $(1,2)$. An extremely rare case of Pancoast's syndrome due to metastatic carcinoma from the stomach is described.

\section{CASE PRESENTATION}

An 81-year-old man was referred to our hospital with complaints of neuritis of the left arm for five months, and cough and hoarseness for two months. Four years previously, he underwent a total gastrectomy due to stomach cancer at the same hospital. Examination revealed Horner's syndrome on the left side, dullness of the apex of the left lung and, by chest radiograph and computed tomography scan, a neoplastic infiltration of the upper lobe of the left lung. Transbronchial biopsy of the tumour revealed proliferation of cancer cells to form a microtubular pattern that was similar to that of the original stomach cancer. The patient began chest irradiation and showed a good clinical response with resolution of his constitutional symptoms. After the chest irradiation, the patient was discharged.

\section{DISCUSSION}

Most of the thoracic inlet tumours producing Pancoast's syndrome have arisen in the pulmonary parenchyma, but others have spread from the larynx, pleura and breast (3). The stomach is an extremely unusual site for a metastatic thoracic inlet tumour from extrathoracic malignancy, and only one case has been reported previously (3). A small number of cases of Pancoast's syndrome are caused by matastatic tumours; however, timely diagnosis of these conditions is crucial, because a certain number of these diseases are potentially curable $(4,5)$. Therefore, presumptive diagnosis of lung cancer should not be made without histological proof. Although obtaining a tissue diagnosis is often difficult with apical lesions, transbronchial or percutaneous needle biopsy is the procedure of choice.

\section{REFERENCES}

1. Pancoast HK. Importance of careful roentgen-ray investigation of apical chest tumors. JAMA 1924;83:1407-11.

2. Pancoast HK. Superior pulmonary sulcus tumor: Tumor characterized by pain, Horner's syndrome, destruction of bone and atrophy of hand muscles. JAMA 1932;99:1391-6.

3. Herbut PA, Watson JS. Tumor of the thoracic inlet producing the Pancoast syndrome. Arch Pathol 1946;42:88-103.

4. Johnson DR, Hainthworth JD, Greco FA. Pancoast syndrome and small cell lung cancer. Chest 1982;82:602-6.

5. Arcasoy SM, Bajwa MK, Jett JR. Non-Hodgkin's lymphoma presenting as Pancoast's syndrome. Respir Med 1997;91:571-3.

Division of Respiratory Medicine, Institute of Clinical Medicine, University of Tsukuba, Tsukuba-city, Japan

Correspondence and reprints: Hiroaki Satoh, Division of Respiratory Medicine, Institute of Clinical Medicine, University of Tsukuba,

Tsukuba-city, 305-8575, Japan. Telephone +81-298-53-3210, fax +81-298-53-3320, e-mail hirosato@md.tsukuba.ac.jp 


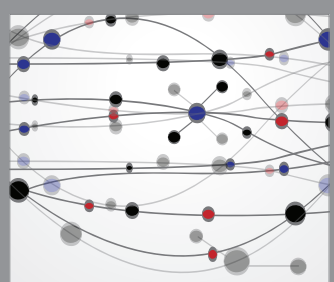

The Scientific World Journal
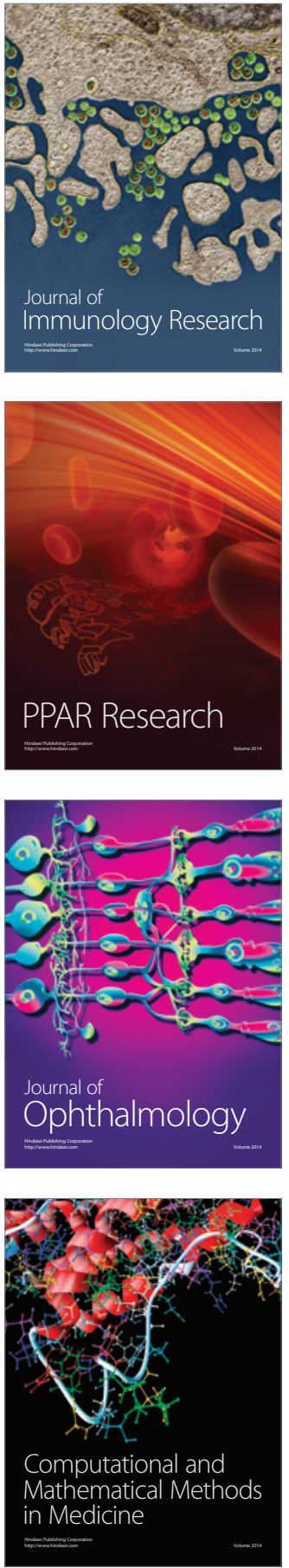

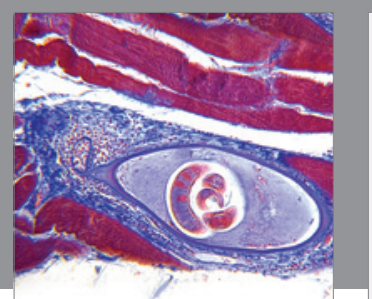

Gastroenterology Research and Practice

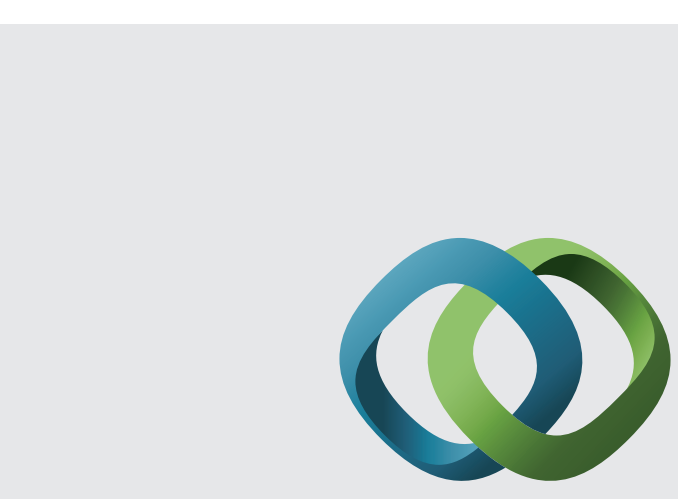

\section{Hindawi}

Submit your manuscripts at

http://www.hindawi.com
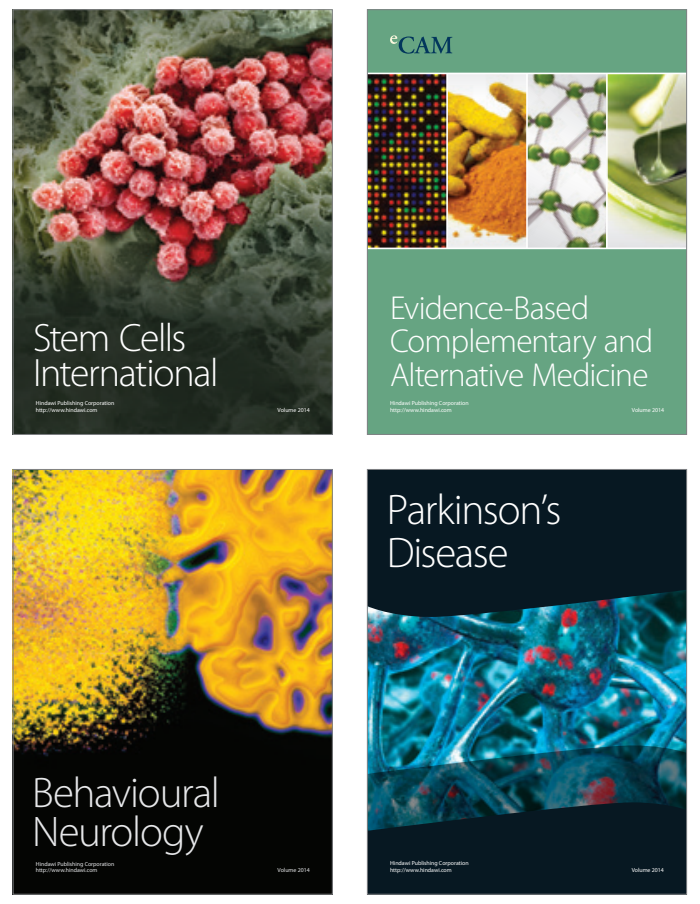
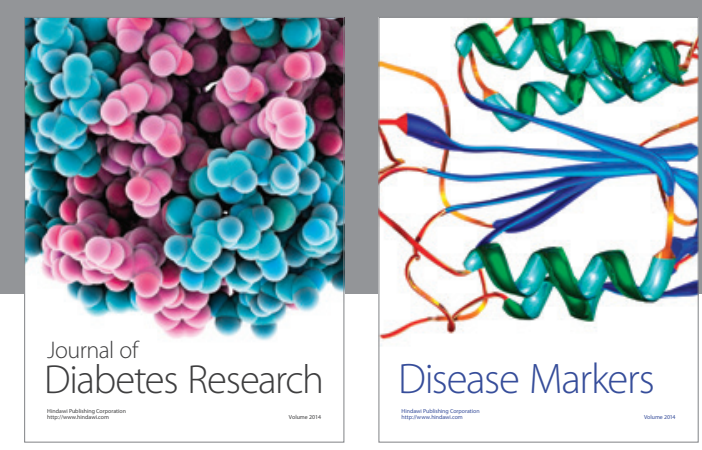

Disease Markers
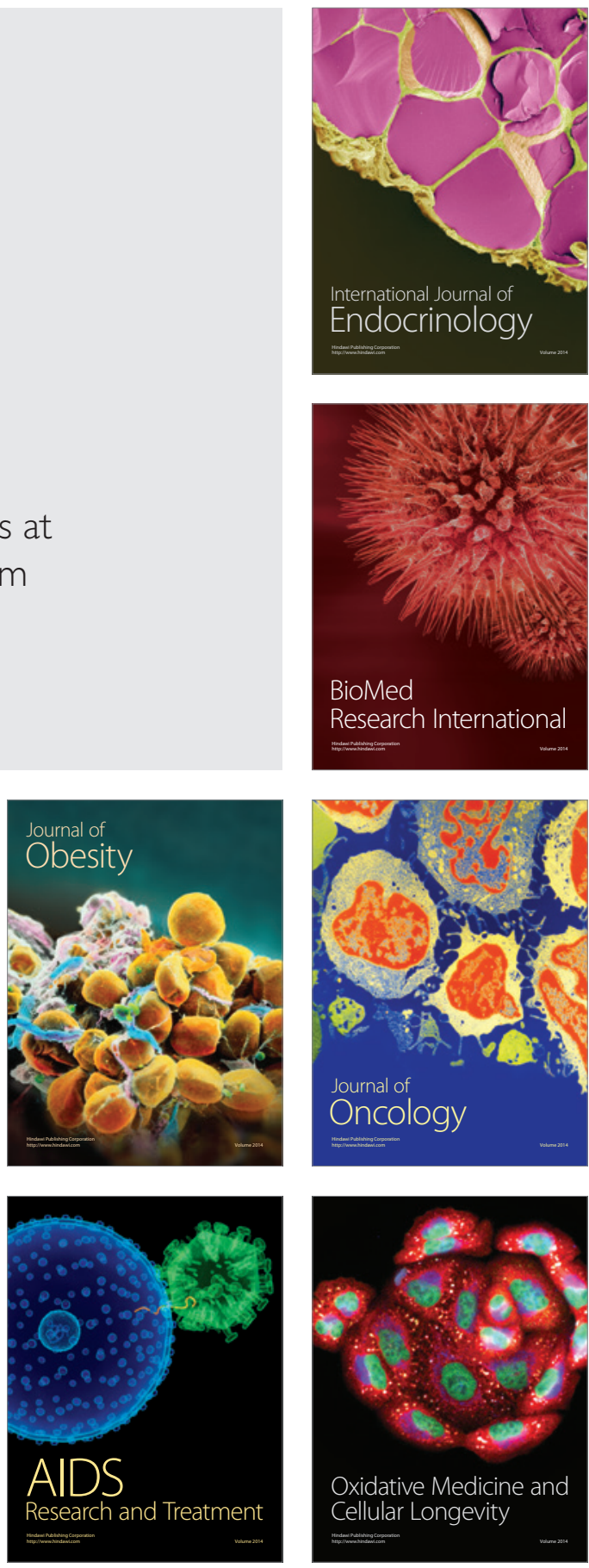